\title{
A CONSTRUÇ̃̃o HISTÓRICA DO CORPO FEMININO
}

\author{
Ana Maria Colling ${ }^{(*)}$
}

\section{Resumo}

A proposta deste texto é fazer uma genealogia/desconstrução do corpo feminino, embasada nos pressupostos teóricos de Michel Foucault. Apresentamos diversas práticas discursivas e práticas não discursivas que construíram o corpo feminino através da história.

Palavras chave: Corpo Feminino. Gênero. Discurso. Foucault.

\begin{abstract}
The purpose of this paper is to genealogy / deconstruction of the female body, based on theoretical assumptions of Michel Foucault. We present various discursive practices and non-discursive practices that built the female body throughout history.
\end{abstract}

Keywords: Feminine Body. Gender. Speech. Foucault.

\section{Introdução}

Nosso corpo tem muito pouco de nós mesmas. Ele é simplesmente um resultado de discursos e de práticas. Ele é, portanto, um efeito histórico. Para demonstrar os variados discursos e práticas que inventaram o corpo feminino (e o corpo masculino evidentemente, como o modelo perfeito) me utilizarei de quem gosto e que me fornecem ferramentas teóricas para análise - Michel Foucault e Jacques Derrida em seus conceitos de Genealogia e Desconstrução, problematizando a linguagem e os discursos.

Apesar das diferenças entre estes dois autores, Foucault e Derrida com suas construções de Genealogia e Desconstrução, no contexto deste texto sobre a construção histórica do corpo feminino, exercem um papel pedagógico. Eles possibilitam analisar a história do corpo feminino e sua desqualificação histórica através das práticas

(*) Professora Visitante Sênior (Capes) na Universidade Federal de Dourados (UFGD) onde atua no PPG de História no Laboratório de Estudos de Gênero, História e Interculturalidade (LEGHI) e na Cátedra da Unesco - Diversidade Cultural, Gênero e Fronteiras. E-mail: acolling21@yahoo.com.br. 
discursivas e das práticas não discursivas. Pois é o corpo o alvo privilegiado nas relações de poder e saber e nas práticas, inclusive jurídicas. Para Silvana Goellner,

\begin{abstract}
O corpo é produto de uma construção cultural, social e histórica sobre o qual são conferidas diferentes marcas em diferentes tempos, espaços, conjunturas econômicas, grupos sociais, étnicos etc. Ou seja, não é algo dado a priori, nem mesmo é universal: é provisório, mutável e mutante, suscetível a inúmeras intervenções consoante o desenvolvimento científico e tecnológico de cada cultura, bem como suas leis, seus códigos morais e sua linguagem, visto que ele é construído também a partir daquilo que dele se diz. (...) Educa-se o corpo na escola e fora dela: na religião, na mídia, na medicina, nas normas jurídicas, enfim, em todos os espaços de socialização nos quais circulamos cotidianamente. ${ }^{1}$
\end{abstract}

$\mathrm{Na}$ história das mulheres a dimensão da linguagem, dos discursos, é uma ferramenta de análise importante, não como meio de representação da realidade, mas como representação. A linguagem não é só vocabulário, mas discurso que numa relação de saber e poder, determina verdades e nos subjetiva. Segundo Paul Veyne, o discurso para Michel Foucault é algo muito simples: é a descrição mais precisa, de uma formação histórica em sua nudez, são as "molduras" formais do saber. Para Foucault, segundo Veyne

as falsas generalidades e os discursos variam ao longo do tempo; mas a cada época eles passam por verdadeiros. De modo que a verdade se reduz a $\mathrm{um}$ dizer verdadeiro. (...) Explicitar um discurso, uma prática discursiva, consistirá em interpretar o que as pessoas faziam ou diziam, em compreender o que supõem seus gestos, suas palavras, suas instituições..." 2

A proposta genealógica de Foucault desafia a origem que vinha acompanhada de uma essência e uma identidade, e, consequentemente, uma verdade universal. O que aprendi com Foucault, quando dizia - "sou simplesmente um historiador", é que os discursos todos podem ser abertos e datados e que as verdades dadas, são simplesmente interpretações num jogo entre poder e saber. O conceito de genealogia é retomado de Nietzsche num texto clássico para historiadores: Nietzsche, a genealogia e a história onde nos mostra que a genealogia é uma pesquisa histórica que

\footnotetext{
${ }^{1}$ GOELLnER, Silvana Vilodre. Corpo. In: Dicionário Crítico de Gênero. Dourados: UFGD, 2015, p. 135.

2 VEYNE, Paul. Foucault: seu pensamento, sua pessoa. Rio de Janeiro: Civilização Brasileira, 2011, pp. 25-26.
} 
se opõe à unicidade da narrativa histórica e a busca da origem - o lugar da verdade, mas procura, ao contrário, a "singularidade dos acontecimentos fora de qualquer finalidade monótona". Para Foucault,

A genealogia não pretende recuar no tempo para restabelecer uma grande continuidade para além da dispersão do esquecimento; sua tarefa não é a de demonstrar que o passado ainda está lá, bem vivo no presente, animando-o em segredo (...) é demarcar os acidentes, os ínfimos desvios - ou ao contrário as inversões completas - os erros, as falhas na apreciação, os maus cálculos que deram nascimento ao que existe e tem valor para nós; é descobrir que na raiz daquilo que nós conhecemos e daquilo que nós somos - não existem a verdade e o ser, mas a exterioridade do acidente. ${ }^{3}$

A Genealogia propõe o trabalho com a diversidade, com a singularidade e não com a verdade, procurando discursos que nos fizeram ser o que somos e ao mesmo tempo a possibilidade de não mais ser, fazer ou pensar o que somos, fazemos ou pensamos. Por isso a importância de Michel Foucault para a história das mulheres, pois se nem sempre foi assim é possivel lutar pela liberdade.

O conceito de desconstrução proposto por Jacques Derrida, insere-se na mesma linha da genealogia de Foucault. Segundo Derrida desconstruir é simplesmente "abrir" o discurso e mostrar nele, não verdades, mas contradições e conflitos. Coloca sob suspeita a possibilidade do significado coerente e sugere uma leitura desconstrutivista de um texto que subverteria o que é aparentemente significativo. Para Derrida a diferença dos sexos, não pertence ao visível, ao definível, mas à interpretação. ${ }^{4}$ Segundo ele, dizer o Homem numa aparente assexuação é sempre dizer o homem masculino, sendo o universalismo apenas o disfarce do falocentrismo. Para muitos autores a desconstrução proposta por Derrida surgiu pela sua preocupação com a alteridade. Para Carla Rodrigues, em Derrida a palavra desconstrução estará relacionada a uma ideia de decomposição, de análise das camadas sedimentadas do pensamento, que formam os elementos discursivos com os quais pensamos.

Assim, o objetivo do pensamento da desconstrução não é “destruir" os autores sobre os quais se debruça, mas escavar as camadas que

\footnotetext{
${ }^{3}$ FOUCAULT, Michel. Nietzsche, a genealogia e a história. In: Microfisica do Saber. Rio de Janeiro: Graal, 1979, p. 21.

${ }^{4}$ DERRIDA, Jacques. A escritura e a diferença. São Paulo: Graal, 1988.
} 
fundamentaram determinados conceitos, a fim de mostrar como estes foram construídos sobre certas premissas ou fundações que encerram os limites de tais conceitos. Desconstruir teria, assim, a função de trazer à tona aquilo que precisou ser recalcado, rebaixado. 5

Segundo Carla Rodrigues, para desconstruir uma determinada oposição, é preciso inverter a hierarquia dos pares binários, entre eles masculino/feminino, proporcionando um novo recurso ao pensamento. Também Haddock-Lobo, nomeia a função ético-política da desconstrução, a de abrir os discursos filosóficos, nomeando as ausências e desnudando outros discursos silenciados, recalcados, pela unidade de um texto. Segundo ele,

assim que surge a ideia de desconstrução, um gesto de pensamento que pretende mostrar a violência autoritária de um sistema fechado que se apresenta como única maneira de compreensão do real e não se mostra, de maneira alguma, como mais uma construção na história das Construções (ou fábulas, como diria Nietzsche) que é a História da Filosofia. ${ }^{6}$ Cult. P. 28

\section{Discursos produzindo o corpo na cultura}

O primeiro discurso a ser utilizado para a designação dos papéis sexuais e sociais é o da matriz filosófica grega. O discurso grego é seguido pelo religioso, através de seu mito de criação, com a expulsão de Adão e Eva do paraíso. Esta simbologia retratada no Velho Testamento foi, e muitas vezes ainda o é, usada para designar papéis e posições de gênero, assim como para criar representações femininas. A Eva pecadora e a Virgem Maria assexuada, imagem dupla feminina como que desde sempre acompanhando a história corporal das mulheres. Os fundadores dos vários discursos, são geralmente homens, que representam, numa relação de poder, o gênero feminino. Discursos recorrentes, sábios ou populares, enraízam-se numa episteme comum. A historiografia acompanhou esta compreensão do mundo e das coisas.

\footnotetext{
${ }^{5}$ RODRIGUES, Carla. Derrida, Jacques (desconstrução, différance). In: Dicionário Crítico de Gênero. Dourados: UFGD, 2015, p. 150.
}

${ }^{6}$ HADDOOCK-LOBO, Rafael. A Desconstrução. In: Revista Cult. São Paulo: Editora Bregantini, outubro de 2014, p. 28. 


\title{
2.1. Discurso grego
}

\section{Platão: "O útero é um animal que vive nelas..."}

O pensamento grego veio até nós de forma pungente, com imagens duradouras resistentes a outras leituras. Preocupou-se com as questões da origem dos homens e da diferença sexual, recolheu informações diversas e influenciou nossa maneira de pensar, como fez Platão (427-347 AC), reformulando a teoria médica. Filosofia e Medicina estavam ligadas a uma arte de viver, que era simultaneamente médica e ética. Em Timeu, um de seus últimos livros, nos fornece a argumentação que vai ser utilizada durante muito tempo sobre a "natureza feminina":

\begin{abstract}
Eis porque nos machos os órgãos genitais são naturalmente insubmissos e autoritários, como animais surdos à voz da razão e, dominados por apetites furiosos, querem comandar tudo. Nas mulheres também e pelas mesmas razões, o que se chama a matriz ou útero é um animal que vive nelas com o desejo de procriar. Quando ele fica muito tempo estéril depois do período da puberdade, ele tem dificuldade em suportar isso, indigna-se, erra por todo o corpo, bloqueia os canais do sopro, impede a respiração, causa um grande incómodo e origina doenças de toda a espécie, até que, o desejo e o amor unindo os dois sexos, eles possam colher um fruto, como numa árvore, e semear na matriz, como num sulco(...) Tal é a origem das mulheres e de todo o sexo feminino ${ }^{7}$
\end{abstract}

É Platão que inaugura a teoria da matriz, do útero como animal raivoso, dando identidade à mulher. Inicia-se aí o culto à reprodução e a crítica ao celibato feminino. Esta proposta irá desembocar mais tarde na histeria, caracterizada como uma doença feminina por excelência, e entre as causas de sua origem a "falta de homem". É a incompletude da mulher sendo teorizada.

\section{Hipócrates: "a semente macha é mais forte que a semente fêmea"}

Hipócrates (460/377 A.C.) o maior médico da Antigüidade, incorporou os saberes médicos e de cura do corpo condensados por Platão e Aristóteles, que

\footnotetext{
${ }^{7}$ PLATÃO. Diálogos: Timeu, Critias, o Segundo Alcebiades, Hipias Menor. Belém: UPPA.GEU, 1986, p. 154.
} 
provinham das parteiras sobre as doenças das mulheres, ligados à menstruação, parto, menopausa, etc. Filiava-se à concepção platônica da circulação do útero no interior do corpo da mulher.

A semente da mulher é umas vezes mais forte, outras vezes mais fraca, também é assim para o homem. A semente macha é mais forte do que a semente fêmea. É da semente mais forte que nascerá o produto. Eis como isso se passa: se a semente mais forte vem dos dois lados, o produto é macho; se a semente é mais fraca, o produto é fêmea. (...)se a semente fraca é muito mais abundante do que a forte, esta é vencida e, misturada com a mais fraca, transforma-se em fêmea; se a forte é mais abundante do que a fraca, a fraca é vencida e transforma-se em macho. ${ }^{8}$

O pensamento de Hipócrates e o de Platão fundem-se numa concepção da mulher vista como matriz, como um campo semeado por outro. O homem é a semente, o produtor, a mulher é a reprodutora. A menstruação é destacada por Hipócrates na preocupação com sua saúde e anunciando o papel regulador do homem:

se elas têm relação com os homens, a saúde delas é melhor, menos boa se não têm. Com efeito, por um lado, no coito, as matrizes humidificam-se e deixam de estar secas; ora, quando elas estão demasiado secas, contraem-se fortemente, e esta contracção forte causa dores no corpo. Por outro lado, o coito, aquecendo e humidificando o sangue, torna o caminho mais fácil para a menstruação; ora, se a menstruação não se dá, as mulheres tornam-se doentias. ${ }^{9}$

\section{Aristóteles: "o primeiro desvio é o nascimento de uma fêmea"}

\footnotetext{
${ }^{8}$ Hipócrates apud JOAQUIM, Teresa. Menina e Moça. A construção social da feminilidade. Lisboa: Fim de Século, 1997. p. 81.

${ }^{9}$ Hipócrates apud JOAQUIM, Teresa. Menina e Moça. A construção social da feminilidade. Lisboa: Fim de Século, 1997. p. 83.
} 
Segundo Aristóteles, há duas maneiras de definir as características dos corpos femininos: a analogia e a inferioridade relativamente aos corpos masculinos. Por um lado, a diferença entre machos e fêmeas é uma relação de correspondência: onde os machos possuem um pênis, as fêmeas apresentam um útero, "que é sempre duplo, do mesmo modo que, nos machos, os testículos são sempre em número de dois". Na História dos Animais, a comparação entre masculino e feminino é realizada salientandose as suas diferenças e a mulher aparece com o corpo mais débil, mais fraco:

\begin{abstract}
A fêmea é menos musculada, tem as articulações menos pronunciadas; tem também o pêlo mais fino nas espécies que possuem pêlo, e, nas que os não possuem, o que faz as suas vezes. As fêmeas têm igualmente a carne mais mole que os machos, os joelhos mais juntos e as pernas mais finas. Os seus pés são mais pequenos, nos animais que têm pés. Quanto à voz, as fêmeas têm-na sempre mais fraca e mais aguda, em todos os animais dotados de voz, com excepção dos bovinos: nestes, as fêmeas têm a voz mais grave que os machos. As partes que existem naturalmente para a defesa, os cornos, os esporões e todas a outras partes deste tipo pertencem em certos géneros aos machos, mas não às fềmeas. Em alguns géneros, estas partes existem em ambos, mas são mais fortes e desenvolvidas nos machos. 10
\end{abstract}

O tamanho do cérebro, a diferença entre homens e mulheres, conceito utilizado durante muito tempo para caracterizar a mulher como um ser inferior intelectualmente, e demonstrar a maior inteligência dos homens, aparece nos textos de Aristóteles sobre As Partes dos Animais:

Entre os animais, é o homem que tem o cérebro maior, proporcionalmente ao seu tamanho, e, nos homens, os machos têm o cérebro mais volumoso que as fêmeas. (...) São os machos que têm o maior número de suturas na cabeça, e o homem tem mais do que a mulher, sempre pela mesma razão, para que esta zona respire facilmente, sobretudo o cérebro, que é maior. ${ }^{11}$

Comparando a mulher com uma criança, doente por natureza, envelhecendo mais rapidamente porque "tudo o que é pequeno chega mais rapidamente ao seu fim, tanto nas obras de arte como nos organismos naturais", Aristóteles não cansa

\footnotetext{
${ }^{10}$ Aristóteles apud SISSA, Giulia. Filosofias do Gênero: Platão e Aristóteles e a diferença dos sexos. In: $A$ História das Mulheres no Ocidente. Vol 3. Porto Afrontamento, 1993, p. 102

${ }^{11}$ ARISTÓTELES. Les parties des animaux. Paris: Les Belles Lettres, 1957, p. 41. Tradução livre.
} 
de repetir que as fêmeas são mais fracas e mais frias e, por natureza, apresentam uma deformidade natural. Os seios, que são maiores nas mulheres que nos homens não escapam ao olhar observador do filósofo, que, comparando-os com os músculos peitorais do tórax masculino, "carne compacta", considera-os como intumescências esponjosas, capazes de se encherem de leite, mas moles e rapidamente flácidos.

Assim como Hipócrates, Aristóteles também preocupa-se com o sangue menstrual. É porque a mulher é um ser impuro que ela sofre esta catarse através da menstruação: "Num ser mais fraco deve necessariamente produzir-se um resíduo mais abundante e cuja cocção é menos elaborada”. Este sangue produzido por uma falta de calor, sinal da frieza feminina, constitui a contribuição do animal fêmea para a concepção de uma criança, defende o filósofo no Tratado da Geração dos Animais. A mãe fornece o material inanimado e passivo que é o sangue menstrual:

É na questão da geração que Aristóteles anula o papel da mulher, retiralhe o trabalho de criadora (é o sêmen que desempenha a função do artista, porque constitui em si, potencialmente, a forma), estabelecendo a menoridade e a inferioridade feminina, assim como uma perversidade que advém de seu sexo. A própria forma côncava da "madre" criaria um desejo mais violento, explicável pelo princípio natural do horror ao vácuo. Mas, entre todas as fêmeas, a mulher e a jumenta atingem, com este filósofo, o extremo da lubricidade, pois tinham a particularidade de serem as únicas que se entregavam ao coito durante a gravidez.

Os discursos sobre a imagem da mulher, sua representação, definiam não somente normas de comportamento, como normas jurídicas e preceitos morais, referendados por construções textuais como o relato bíblico da criação e a queda do paraíso ou o Tratado da geração dos animais de Aristóteles. Este filósofo, em especial, exercerá uma grande influência que ainda se mantém viva na tradição da teologia e da filosofia escolástica presente na Igreja Católica. ${ }^{12}$

$12 \mathrm{O}$ discurso aristotélico da desqualificação do feminino, pela comparação com o "corpo perfeito e bem acabado" do homem permanece nos dias de hoje. O tamanho do cérebro será usado em várias temporalidades e espaços. Este livro escrito quase 500 anos antes de cristo, é reivindicado em 1910 no Congresso nacional brasileiro no Rio de Janeiro por ocasião da elaboração do Código Civil Brasileiro que será aprovado em 1916. Para garantir que a mulheres fossem registradas como relativamente incapazes em relação ao marido, (e tudo que disso advinha) um deputado lembrou o filósofo. Se ela tem cérebro menor, necessita ficar sob a guarda de quem pensa e raciocina. Em 2005 o reitor da Universidade de Harvard (EUA) declarou que as mulheres não tem aptidão para ciências e matemática porque tem um cérebro menor que os homens. 


\subsection{Discurso religioso}

$\mathrm{Na}$ Idade Média, o sistema de pensamento aristotélico será o modo de compreender o mundo, os seres e as relações entre eles. O pensamento de Platão e Aristóteles incorporado pela religião cristã será difundido pela Igreja num perfeito casamento entre o discurso filosófico e o religioso. A moral sexual ocidental será fruto deste encontro.

A tradição cristã judaica colaborou de maneira decisiva para a inculcação da inferioridade da mulher. O relato da criação da mulher, bem como a da sua parte na tentação de Adão e sua conseqüente condenação por Deus, danando toda a humanidade, teve efeitos devastadores muito duradouros sobre a imagem da dignidade do feminino.

No universo dos textos jurídicos, a presença desta imagem é constante. Muitos, para referendar a menor dignidade da mulher, recorrem ao seu papel no pecado original e na condenação com que Deus, por isso a fulminou: “À mulher lhe digo: tantas serão tuas fadigas, quantos sejam teus embaraços: com trabalho parirá teus filhos. Teu marido te dominará".

Da condenação bíblica provém a ideia de impureza da mulher, nomeadamente nos períodos femininos da menstruação e do parto, quando estava proibida de freqüentar o templo e acusada de macular as coisas que tocasse. Durante muito tempo, fez parte do imaginário a crença de que a lepra era transmitida pelo toque da mulher menstruada, assim como a concepção de filhos neste período geraria monstros. Na esteira de Aristóteles, acreditava-se que o olhar de uma mulher menstruada embaciava os espelhos.

Na tradição cultural que parte destes “ensinamentos", a mulher permanece sempre marcada por esta mancha original que deve ser continuamente lembrada e assumida. O véu era uma das marcas de vergonha que sempre deveria levar, e o seu comportamento deveria ser continuamente regulado pelas ideias de sujeição e de expiação. O mito de Eva é lembrado pelos contatos com a força do mal, na prática das feiticeiras detentoras de saberes e poderes ensinados por Satanás. Segundo Araújo, 
tal pensamento é expresso no Malleus maleficarum, tratado de demologia publicado em 1486:

Houve uma falha na formação da primeira mulher, por ter sido ela criada a partir de uma costela recurva, ou seja, uma costela do peito, cuja curvatura é, por assim dizer, contrária à retidão do homem. E como, em virtude dessa falha, a mulher é animal imperfeito, sempre decepciona a mente ${ }^{13}$.

O inspirador religioso mais utilizado pelos juristas e pelos misóginos para estabelecer o lugar que o feminino deve ocupar na sociedade é São Paulo, que aconselha à mulher aprender em silêncio e submissão: "Não permito que a mulher ensine ou domine o homem. Que se mantenha em silêncio. Adão foi criado primeiro, e depois Eva. E Adão não foi seduzido, mas a mulher foi-o para o pecado. Apenas se salvará pela geração de filhos, se permanecer na fé, caridade e santificação com sobriedade".

São Paulo não reina sozinho na defesa da superioridade masculina. A defesa da discriminação à custa da degradação da imagem da mulher é apresentada por São Tomás de Aquino, que retoma a teoria paulina da submissão sob um novo fundamento: ela já não era apenas exigida pela pressão das circunstâncias exteriores, mas também pela desigualdade natural dos sexos, pela inferioridade natural da mulher, que é uma deficiência da natureza e, por natureza, de menor valor e dignidade que o homem. 14

O Padre Antônio Vieira (1608-1697), em seus célebres Sermões, também dedicará especial atenção à tentação feminina oriunda do pecado original, contribuindo para a cristalização de estereótipos sobre a mulher:

\footnotetext{
${ }^{13}$ Cfe. ARAÚJO, Emanuel. A arte da sedução: sexualidade feminina na colônia. In: História das mulheres no Brasil. São Paulo: Contexto,1997, p. 46.

${ }^{14}$ Discursos poderosos que se transformam em práticas, atuando decisivamente sobre todas as mulheres e não somente sobre as católicas: em 1822 por ocasião das Cortes Constituintes em Portugal um deputado propôs o direito ao voto a uma viúva, mãe de 6 filhos que sustentava sua casa. Outro deputado responde ao proponente dizendo que este parecer não deve ser discutido porque trata-se do exercício de um direito político e "delles as mulheres são incapazes. Ellas não tem voz nas sociedades publicas: mulier in ecclesia taceat, diz o Apostolo". O deputado recorria a São Paulo - "na Igreja a mulher cala-se". E a proposta do voto não foi discutida. Cf. COLLING, Ana Maria. A construção da cidadania da mulher brasileira. Tese de doutorado, 2000, p. 110.
} 
Todos os trabalhos e calamidades que padecemos na vida, toda a corrupção e misérias a que estamos sujeitos na morte, todos os males, penas e tormentos, (...) tiveram seu princípio e trazem sua origem desde o pecado, por isso chamado original. De toda esta infelicidade foi causa uma mulher, e que mulher? Não alheia, mas própria, e não criada em pecado, mas inocente, e formada pelas mãos do mesmo Deus. (...) Todas as dores, todas as enfermidades, todas as fomes, todas as pestes, e guerras, todas as destruições de cidades e reinos, todas as tempestades, terremotos, raios do céu e incêndios, (...) que outro princípio ou causa tiveram, senão a intemperança e castigo daquela mulher, não tomada ou roubada a outrem, senão própria, e dada pelo mesmo Deus ao homem: mulier quam dedisti mihi $(\mathrm{Gn} 3,12)^{15}$.

Durante a Idade Média, as mulheres gozam de uma situação ambígua. A Igreja recolhe nos seus conventos muitas mulheres privadas do apoio masculino, envolvidos pelas numerosas guerras. Por outro lado, persegue impiedosamente como "feiticeiras" todas as mulheres que procuram aprofundar os seus conhecimentos e enveredam pelo perigoso caminho da "magia". Milhares de mulheres foram torturadas e mortas durante as terríveis "caça as bruxas" que, sob a capa da religião, esconderam muitas vezes perseguições políticas. A caça às bruxas teve seu auge nos séculos XVI e XVII e são perseguidas especialmente mulheres parteiras que detêm saber no campo da sexualidade.

A ideia da mulher luxuriosa, fonte dos males e de pecado não desaparecerá imediatamente e nunca de todo. Ao lado desta nova visão da sexualidade feminina como uma sexualidade passiva, inicia-se também uma configuração do modelo da domesticidade, que transformar-se-á no "anjo do lar" do século XIX. O Concílio de Trento (1545-1563) no qual definiu-se o caráter sacramental do casamento, comportará mudanças para as mulheres devido ao reforçamento do controle da moralidade.

São Tomás de Aquino, também um bom leitor de Aristóteles, influenciará os juristas, que consideram as mulheres carentes de capacidades para se regerem a si próprias, devendo estar, por isso mesmo, sujeitas à tutela de alguém. Explica que os fundamentos desta sujeição - que é diferente da do escravo - são altruístas, destinando-se a proteger a própria mulher. Antes do casamento,

${ }^{15}$ VIEIRA, Antonio Padre. Sermões. Vol. 3. Porto: Livraria Schardron, 1959, p. 240-1. 
estão sob a patria potestas do pai, depois, como pupilas, sob a curatela do marido: assim assimilou o direito os ensinamentos religiosos.

Se a lúxuria havia perdido a humanidade com Eva no paraíso, o remédio contra estes propalados defeitos das mulheres seria uma constante vigilância sobre os seus costumes e um rigoroso confinamento ao mundo doméstico.Quando instala-se o casamento monogâmico, torna-se necessária a criação do mito da Virgem Maria, porque já não é possível englobar todas as mulheres no mito de Eva. O casamento necessita de uma imagem feminina purificada na exaltação à maternidade. Esta construção mítica tornou-se o modelo ideal de mulher, inatingível. Os que defendiam o princípio igualitário contido na lição dos Evangelhos logo viam as suas limitações. Afastando as mulheres das funções sacerdotais e de certas funções litúrgicas, que reservou aos homens, a Igreja lançava a semente de um regime discriminatório.

Foi necessário esperar a publicação da Encíclica Pacem in Terris (1963), pelo papa João XXIII, para romper com a doutrina tradicional da Igreja, defendida desde São Paulo, da hierarquia entre os sexos na vida familiar e a conseqüente submissão da mulher ao marido. A Encíclica aceita a emancipação da mulher e consagra a igualdade de direitos e obrigações do casal na vida familiar: "Torna-se a mulher cada vez mais cônscia da própria dignidade humana, não merece mais ser tratada como um objeto ou um instrumento, reivindica direitos e deveres consetâneos com a sua dignidade de pessoa, tanto na vida familiar como na vida social". Na tentativa de enterrar de uma vez por todas os fundamentos hierarquizados da Igreja, diz que "no nosso tempo estão superadas seculares opiniões que admitem classes inferiores de homens e classes superiores, derivadas da situação econômico-social, sexo ou posição política". ${ }^{16}$

O papa João Paulo II, na Carta Apostólica Mulieris dignitatem (1988), em um capítulo intitulado "A dignidade da mulher", consolida com fontes bíblicas a igual dignidade da mulher e do homem contra a discriminação e a inferioridade a que a história tem condenado o gênero feminino. O papa se propõe a dizer "a verdade" sobre o homem e a mulher, dizê-la e legitimá-la com o apoio dos livros sagrados. Mas a Igreja

\footnotetext{
${ }^{16}$ Papa João XXIII. Encíclica Pacem in Terris. Lisboa: Sampedro, 1964
} 
que João Paulo II representa continua negando às mulheres o acesso ao sacerdócio. São iguais aos homens, certamente, mas não para serem sacerdotisas, para fazerem o uso da palavra.

João Paulo II lembra que "Cristo foi ante seus contemporâneos o promotor da verdadeira dignidade da mulher e da vocação correspondente a esta dignidade". Segundo ele, Jesus gostava de estar entre as mulheres, tratá-las como iguais e falar com elas de questões profundas e importantes. Recuperar a dignidade da mulher significa reivindicar a igualdade, mas uma igualdade "diferente", não uma igualdade que masculinize a mulher, mas recupere a sua feminilidade, lembra ele. Quanto ao sacedócio, recorda João Paulo II que o mesmo Cristo elegeu como apóstolos doze homens. Ele, que tanto apreciou as mulheres, as excluiu do sacerdócio. Se assim o fez, foi porque "deste modo desejava expressar a relação entre o homem e a mulher, entre o que é feminino e o que é masculino."17

Esta Carta Apostólica reveste-se de grande valor porque demonstra o reconhecimento da Igreja de que é necessária a relação igualitária entre os dois sexos para uma vida social harmoniosa, apesar de insistir na natureza masculina de Jesus, como legitimação da relação hierarquizada dos homens e das mulheres com relação à Igreja, mas também com o poder.

\subsection{Discurso médico}

A revolução científica não serviu para demonstrar a falsidade dos argumentos filosóficos e religiosos sobre a inferioridade das mulheres. Na hora de estudar a anatomia e a fisiologia femininas, os homens, revestidos de uma capa cientificista, reafirmaram a tradição baseada em Aristóteles e na medicina de Hipócrates. Galeno, médico grego, nasceu por volta de 130 D.C. e suas teorias, juntamente com as de Aristóteles, vigoraram até o século XVII, tendo uma grande influência na explicação da natureza feminina.

\footnotetext{
${ }^{17}$ Papa Paulo II.Carta Apostólica. A dignidade e a vocação da mulher: Mulieris Dignitatem. Braga: A O,
} 1988. 
A descrição anatômica dos órgãos sexuais feita pelo médico grego representa os femininos como o inverso dos masculinos, tudo explicado por uma falta de calor, que fez com que os órgãos genitais femininos não descessem, mantendo-se interiores:

\begin{abstract}
Representai-vos as primeiras (as partes) que se oferecem à vossa imaginação, quaisquer que sejam, voltem para fora as da mulher, dobrem para o interior as do homem, e achá-las-ão semelhantes umas às outras. Primeiramente suponham comigo as do homem recolhidas e estendendo-se interiormente entre o recto e a bexiga; nesta suposição, o recto ocuparia o lugar das matrizes, com os testículos de cada lado da parte externa; o pénis do macho tornar-se-ia o colo da cavidade que se produz, e a pele da extremidade do pénis, que chamamos agora prepúcio, tornar-se-ia a vagina da mulher. Suponham inversamente que a matriz se volta e cai para fora, os seus testículos não se achariam necessariamente dentro da sua cavidade; não os envolveria ela como um escroto? O colo até aí solto dentro do pireneu, pendendo nesta altura, não se tornaria o membro viril, e a vagina da mulher, que é um apêndice cutâneo desse colo, não tornaria o lugar do que chamamos prepúcio? ${ }^{18}$
\end{abstract}

O discurso médico não havia mudado muito desde a formação do corpus hipocrático grego e, somando-se ao discurso religioso, angariava mais argumentos. A "teoria do ventre errante" atribui todos os males da natureza à sua matriz, que é como um animal faminto que somente descansa quando a mulher está grávida.

Para este discurso médico, o útero é o órgão que dá identidade à mulher, que explica as características de uma físiologia e de uma psicologia vulneráveis. A "sufocação da matriz" ou "furor uterino", movimentos extraordinários do útero, que tal como um animal, se agita por todo lado em convulsões violentas, é a origem da histeria. A causa do ataque histérico é sempre a mesma: um vapor venenoso produzido pela matriz e que, ao passar pelas artérias e pelos poros do corpo, lesa todo o organismo, até ao cérebro.

Esta sujeição da mulher ao seu sexo transforma-se em submissão necessária ao homem. É um discurso simbólico que desempenha a função de justificar a supremacia do homem aos olhos de todos os membros da sociedade, das mulheres e dos homens, transformando o homem na medida de todas as coisas. O pensamento

${ }^{18}$ Galeno, Apud JOAQUIM, Teresa, Menina e Moça. A construção social da feminilidade. Lisboa: Fim de Século, 1997. p. 116. 
médico, em nome de um determinismo natural, confina a feminilidade em uma esfera que a ordem social lhe destina: a mulher sã e feliz é a mãe de família, guardiã das virtudes dos valores eternos.

\subsection{Discurso psiquiátrico}

O pensamento do século XIX respaldava as antigas tradições sobre as mulheres com novos conhecimentos "científicos". O discurso da psiquiatria desenvolvese juntamente com o discurso médico. A autoridade bíblica com respeito à subordinação feminina foi confirmada ou substituída pela autoridade biológica. A mulher, cujo ser é afetado pela sexualidade no discurso médico, logo passa a ser vista como um ser doentio, com crises freqüentes, afetada pelas paixões, pelos romances.

O sistema reprodutivo da mulher continuava sendo um mistério, exageravam-se os efeitos supostamente debilitadores da menstruação, tida como uma tensão tremenda em um sistema já débil por si. Jules Michelet afirmava que, devido à menstruação, "durante 15 ou 20 dias de 28 (poderíamos dizer que quase sempre), uma mulher é não somente uma inválida, senão uma inválida ferida. Ela sofre sem cessar a eterna ferida do amor". ${ }^{19}$ Nos dias de menstruação as mães recomendavam às suas filhas que não realizassem qualquer atividade física e, especialmente, qualquer esforço intelectual.

A partir do final do século XVIII, a histeria passa a figurar como doença mental feminina. A concepção do corpo feminino é a de um corpo saturado de sexualidade, mas no qual se renova a sociedade - a sua função social -, sendo, pois, necessário, através de dispositivos médicos, educativos, familiares, torná-lo capaz dessa tarefa. Foi sob esta definição que, segundo Michel Foucault em Vontade de Saber, foi produzida a histerização do corpo da mulher:

\footnotetext{
tríplice processo pelo qual o corpo da mulher foi analisado qualificado e desqualificado - como corpo integralmente saturado de sexualidade; pelo qual, este corpo foi integrado, sob o efeito de uma patologia que lhe seria intrínseca, ao campo das práticas médicas; pelo qual, enfim, foi posto em comunicação orgânica com o corpo social (cuja fecundidade regulada deve assegurar), com o espaço familiar (do qual deve ser elemento substancial e funcional) e com a vida das crianças (que produz e deve garantir, através de uma responsabilidade
}

\footnotetext{
${ }^{19}$ MICHELET, Jules. A Mulher. São Paulo: Martins Fontes, 1995.
} 
biológico-moral que dura todo o período da educação) : a Mãe, com sua imagem em negativo que é a 'mulher nervosa', constitui a forma mais visível desta histerização ${ }^{20}$

Em 1838 foi defendida a primeira tese sobre a histeria feminina, na Faculdade de Medicina do Rio de Janeiro, não fugindo à tradição de que esta doença era provocada pela "sufocação da matriz". Rodrigo Maurício Júnior propõe a tese de que a histeria está ligada à sexualidade e é uma "moléstia, de que o útero é a sede". O médico, não consegue esconder medo e fascínio ao desenhar o perfil da possível histérica:

\begin{abstract}
As mulheres nas quais predominar uma superabundância vital, um sistema sanguíneo, ou nervoso mui pronunciado, uma cor escura, ou vermelha, olhos vivos e negros, lábios dum vermelho escarlate, boca grande, dentes alvos, abundância de pêlos e de cor negra, desenvolvimento das partes sexuais, estão também sujeitas a sofrer desta neurose..$^{21}$
\end{abstract}

O ideal masculino da mulher, a maternidade, era vista como o único caminho da sanidade feminina. Aquela que não quisesse ou não pudesse realizá-la não teria outro fim senão a insanidade mental. A velha concepção da "matriz" tomando conta do intelecto feminino. A maternidade também aparecia como a saída contra o prazer sexual feminino, considerado anormal, pois entendia-se que o instinto materno anulava o instinto sexual. A passagem para o século XX não abandona a associação entre mulher e histeria.

\title{
2.5. Discurso psicanalítico
}

A psicanálise nasce através da histeria, da doença das mulheres, com Sigmund Freud (1856-1939), primeiro a tomar a diferença entre os sexos como objeto. Opera uma dupla ruptura filosófica: propõe uma teoria da sexualidade e uma nova teoria do conhecimento, fundada sobre a noção do inconsciente. Esta última revoluciona profundamente a representação que o homem tem do conhecimento de si e do mundo.

\footnotetext{
${ }^{20}$ FOUCAULT, Michel. História da sexualidade. A vontade de saber. Rio de janeiro: Graal, 1979, p. 98.

${ }^{21}$ Junior, apud ENGEL, Magali. Psiquiatria e feminilidade. In: História das mulheres no Brasil. São Paulo: Contexto, 1997, p. 344.
} 
Mas a teoria da sexualidade nada tem de novo, lembrando muito a medicina filosófica que destinava papel às mulheres.

O discurso de Freud, emprestando mais uma vez um caráter científico à delimitação dos papéis sociais, é reconhecido pela sua originalidade de pôr em evidência a importância da sexualidade na constituição da personalidade feminina. Por outro lado, sua concepção da psicologia das mulheres não fica nada a dever aos padrões e valores culturais patriarcais e falocráticos. Sua teoria da psicologia feminina deu novo alento à antiga tradição do domínio masculino com a autoridade que lhe dava ser a mais nova das ciências.

Foi o discurso da histeria feminina cujos sintomas são a languidez, o cansaço, a melancolia e o desinteresse das mulheres, desenvolvido nos séculos XVIII e XIX, que fascinou Freud. Segundo ele, a sexualidade feminina é desenhada a partir do confronto com a "perfeição" masculina e marcada por uma insatisfação da mulher, de sua onsciência da falta do pênis e na inveja dele. O feminino é definido como falta, privação, impotência - a mulher é um homem "incompleto".

As ideias sobre as mulheres, Freud resumiu em seu ensaio Feminilidade, no qual defende que o momento culminante na vida de uma mulher se produz quando esta dá à luz um filho homem. Desta maneira, ela criaria um substitutivo ao pênis e resolveria o problema da inveja do mesmo. Mas, mesmo assim a mulher seguiria sendo inferior em muitos outros aspectos: "O fato de que se deve considerar as mulheres deficientes, em referência ao sentido de justiça, está sem dúvida alguma relacionado com o predomínio da inveja (do pênis) em sua vida intelectual". ${ }^{22}$

Enquanto que para Aristóteles a mutilação feminina se devia a uma falta de calor e, portanto, de semente; para Freud, a castração se deve à descoberta da falta de pênis nas meninas: “o resultado das duas 'descrições' é o mesmo: a diferenciação da espécie em dois sexos é substituída, ora por um modelo masculino único, ora por um só sexo visível". Dois discursos tão distantes temporalmente, mas fechando os elos da corrente da normatização sobre o que é e para quê serve uma mulher.

\footnotetext{
${ }^{22}$ FREUD, Sigmund. A Feminilidade. Novas conferências introdutórias sobre psicanálise e outros
} trabalhos. Rio de janeiro: Imago, 1994. 
Sylviane Agacinski, em Política dos Sexos, faz uma aproximação entre Freud e Aristóteles no qual a mulher (a fêmea em geral) não é capaz de produzir uma semente, apenas o macho pode ser considerado fecundo. Em sua analogia entre estes dois pensadores tão significativos para a cultura ocidental, como matrizes para outros discursos, funciona a mesma estrutura da diferença na oposição presença-ausência, onde a mulher aparece como "macho mutilado". Enquanto que para Aristóteles a mutilação feminina se devia a uma falta de calor e, portanto, de semente; para Freud, a castração se deve à descoberta da falta de pênis nas meninas: "o resultado das duas 'descrições' é o mesmo: a diferenciação da espécie em dois sexos é substituída, ora por um modelo masculino único, ora por um só sexo visível"23.

\section{Conclusão}

Os pensadores e escritores importantes, os livros sagrados e os sermões, os contos e os ditos populares insistiam na necessidade da subordinação feminina. Em Política, quando afirma que Esparta havia decaído porque as mulheres exerciam influência demasiada, Aristóteles declarava que o "o valor do homem se mostra no mando, o da mulher na obediência".

A subordinação e a inferioridade das mulheres se converteram em tradição, tanto na vida cotidiana como nos escritos eruditos. $O$ ideal masculino continuou sendo o da esposa fiel, serviçal e submissa; o pesadelo continuou sendo as "más mulheres, voluntariosas e variáveis, falsas, volúveis e frívolas". A história acompanhou estes discursos recorrentes, que também exerceram influência decisiva na elaboração dos Códigos Civis e das Constituições de todo o Ocidente, justificando a situação de inferioridade em que o sexo feminino foi colocado.

$\mathrm{O}$ discurso da diferença biológica entre homens e mulheres assume um caráter universal e imutável, construído e reconstruído no entrecruzamento dos mais variados discursos, como o da Religião, da Filosofia, da Medicina, da Biologia, da Psicanálise, da Educação, do Direito etc., atravessando todas as relações sociais e, dessa maneira, legitimando-se.

${ }^{23}$ AGACINSKI, Sylviane. Política dos sexos. Rio de Janeiro: Nova Fronteira, 1999, p. 44. 
Quando na atualidade, ficamos estarrecidas com os números de casos de violência contra as mulheres, apesar das leis igualitárias e da Lei Maria da Penha que tenta coibir esta violência, o exercício da desconstrução e da genealogia nos oferece pistas de entendimento. A histórica desqualificação do feminino, a desconsideração com o corpo da mulher, fizeram morada, tanto em homens como em mulheres.

Encerro este texto com Michel Foucault que me permitiu, como historiadora pensar diferente do que pensava até então:

\begin{abstract}
Quanto ao motivo que me impulsionou foi muito simples. Para alguns, espero, esse motivo poderá ser suficiente por ele mesmo. É a curiosidade - em todo caso, a única espécie de curiosidade que vale a pena ser praticada com um pouco de obstinação: não aquela que procura assimilar o que convém conhecer, mas a que permite separar-se de si mesmo. De que valeria a obstinação do saber se ele assegurasse apenas a aquisição de conhecimentos e não, de certa maneira, e tanto quanto possível, o descaminho daquele que conhece? Existem momentos na vida onde a questão de saber se se pode pensar diferentemente do que se pensa, e perceber diferentemente do que vê, é indispensável para continuar a olhar ou a refletir. ${ }^{24}$
\end{abstract}

\title{
Referências
}

AGACINSKI, Sylviane. Política dos sexos. Rio de Janeiro: Nova Fronteira, 1999.

ARAÚJO, Emanuel. A arte da sedução: sexualidade feminina na colônia. In: História das mulheres no Brasil. São Paulo: Contexto,1997.

ARISTÓTELES. Les parties des animaux. Paris: Les Belles Lettres, 1957.

COLLING, Ana Maria. Tempos diferentes, discursos iguais. A construção histórica do corpo feminino. Dourados: UFGD, 2014.

A construção da cidadania da mulher brasileira. PUCRS,Tese de doutorado, 2000, p. 110.

DERRIDA, Jacques. A escritura e a diferença. São Paulo: Graal, 1988.

ENGEL, Magali. Psiquiatria e feminilidade. In: História das mulheres no Brasil. São Paulo: Contexto, 1997.

FOUCAULT, Michel. História da Sexualidade. O Uso dos Prazeres. Rio de Janeiro: 
Graal, 1984.

. Nietzsche, a genealogia e a história. In: Microfísica do Saber. Rio de janeiro:

Graal, 1979.

. História da sexualidade. A vontade de Saber. Rio de janeiro: Graal, 1979.

. A ordem do discurso. São Paulo: Loyola, 1996.

FREUD, Sigmund. A Feminilidade. Novas conferências introdutórias sobre psicanálise e outros trabalhos. Rio de janeiro: Imago, 1994.

GOELLNER, Silvana Vilodre. Corpo. In: Dicionário Crítico de Gênero. Dourados: UFGD, 2015.

HADDOOCK-LOBO, Rafael. A Desconstrução. In: Revista Cult. São Paulo: Editora Bregantini, outubro de 2014.

JOAQUIM, Teresa. Menina e Moça. A construção social da feminilidade. Lisboa: Fim de Século, 1997.

MICHELET, Jules. A Mulher. São Paulo: Martins Fontes, 1995.

PAPA João XXIII. Encíclica Pacem in Terris. Lisboa: Sampedro, 1964.

PAPA Paulo II.Carta Apostólica. A dignidade e a vocação da mulher: Mulieris Dignitatem. Braga: A O, 1988.

PLATÃO. Diálogos: Timeu, Critias, o Segundo Alcebiades, Hipias Menor. Belém: UPPA.GEU, 1986.

RODRIGUES, Carla. Derrida, Jacques (desconstrução, différance). In: Dicionário Crítico de Gênero. Dourados: UFGD, 2015.

SISSA, Giulia. Filosofias do Gênero: Platão e Aristóteles e a diferença dos sexos. In: $A$ História das Mulheres no Ocidente. Vol 3. Porto: Afrontamento, 1993.

VEYNE, Paul. Foucault: seu pensamento, sua pessoa. Rio de Janeiro: Civilização Brasileira, 2011.

VIEIRA, Antonio Padre. Sermões. Vol. 3. Porto: Livraria Schardron, 1959. 
